\title{
The combined impact of ankle-brachial index and transcutaneous oxygen pressure on mortality in patients with type 2 diabetes and foot ulcers
}

\author{
Katarina Fagher ${ }^{1,2}$ (D) Magnus Löndahl ${ }^{1,2}$
}

Received: 11 February 2021 / Accepted: 29 April 2021 / Published online: 8 May 2021

(c) The Author(s) 2021

\begin{abstract}
Aims A diabetic foot ulcer (DFU) is associated with increased cardiovascular risk and mortality, independently of ulcer etiology (ischemic, neuro-ischemic or neuropathic). Ankle-brachial index (ABI) is the most commonly used test when diagnosing peripheral macrovascular disease and is a well-known marker for increased cardiovascular risk. Transcutaneous oxygen pressure $\left(\mathrm{TcPO}_{2}\right)$ is considered to better evaluate microvascular function and has in previous studies shown correlations with both wound healing and survival. The aim of this study was to evaluate the combined impact of a low $\mathrm{TcPO}_{2}$ $(<30 \mathrm{mmHg})$ and a pathological ABI $(<0.9$ or $\geq 1.4)$ on three-year mortality in patients with DFU.

Methods Type 2 diabetes patients aged $<90$ years, with at least one DFU who underwent vascular assessment with ABI and $\mathrm{TcPO}_{2}$ were screened for participation. The primary endpoint was mortality after three years, assessed from the National Death Registry in Sweden.

Results The study enrolled 235 participants with a median age of 76 years. Individuals with either an abnormally high or low $\mathrm{ABI}$ in combination with a low $\mathrm{TcPO}_{2}$ had the worst survival rates, with three-year mortality of $54 \%$, compared to $42 \%$ in those with one abnormal variable (either $\mathrm{ABI}$ or $\mathrm{TcPO}_{2}$ ), and $21 \%$ in those with normal $\mathrm{ABI}$ and $\mathrm{TcPO}_{2}$.

Conclusions Combining $\mathrm{ABI}$ and $\mathrm{TcPO}_{2}$ when risk stratifying DFU patients seems to provide additional predictive information, not only concerning ulcer healing and limb salvage, but also on survival.
\end{abstract}

Keywords Diabetic foot $\cdot$ Microvascular disease $\cdot$ Macrovascular disease

\section{Introduction}

A diabetic foot ulcer (DFU) is a common and serious complication of diabetes, with a life-time incidence of approximate $15 \%$ [1]. It is a major cause of morbidity, reduced quality of life, and is today the leading cause of lower-limb amputations in the western world [2]. Further, a DFU has huge consequences on survival, and might serve as a marker for an advanced, general vascular disease associated with poor prognosis [3]. Individuals with DFU have a 2.5 times

Managed by Massimo Porta .

Katarina Fagher

Katarina.fagher@med.lu.se

Clinical Sciences in Lund, Lund University, Lund, Sweden

2 Department of Endocrinology, Skåne University Hospital, Lund, Sweden higher mortality risk compared individuals with diabetes but without a DFU $[4,5]$.

Presence of peripheral arterial disease (PVD) with a low ankle-brachial index (ABI) is a well-known risk factor for concomitant cardiovascular disease as well as increased mortality [6-8]. However, when evaluating survival among individuals with diabetes, not only macrovascular complications but also the presence of microvascular complications seem to be important predictors for survival [9]. Transcutaneous oxygen pressure $\left(\mathrm{TcPO}_{2}\right)$ is a non-invasive method assessing tissue perfusion and is considered to better reflect the microvascular function in the skin [10].

A reduced $\mathrm{TcPO}_{2}$ level has in previous studies been associated with both lower ulcer healing rates and increased mortality $[11,12]$. Whether a combination of a pathological ABI and a low $\mathrm{TcPO}_{2}$ could provide further prognostic information on survival compared to $\mathrm{ABI}$ alone has previously not been studied. 
The primary aim of this study was to evaluate the combined impact of a low $\mathrm{TcPO}_{2}$ level $(<30 \mathrm{mmHg})$ and a pathologically low or high ABI $(<0.9$ or $\geq 1.4)$ on threeyear mortality in people with DFU. Secondary aims were to evaluate the combined impact of a low $\mathrm{TcPO}_{2}$ and a pathological $\mathrm{ABI}$ on ulcer healing and amputation rates.

\section{Methods}

For this study, we screened all patients who performed a vascular assessment with Periflux 5000 diagnostic instrument (Perimed AB, Stockholm Sweden) at our DFU-unit at Skane University Hospital in Lund between years 2013 and 2015. Inclusion criteria were type 2 diabetes, age $<90$ years and at least one ulceration (malleoli or below). Exclusion criteria were lack of $\mathrm{ABI}$ or $\mathrm{TcPO}_{2}$ value. All patients were treated according to international guidelines regarding the diabetic foot and were referred to vascular intervention when indicated [13]. Patients were followed at our DFU-unit at a regular basis until ulcer healing or until major amputation. Ulcer healing was defined as complete epithelialization without a major amputation, and this parameter was retrospectively evaluated from patients' medical records after 3 and 12 months. Major amputation was defined as amputation level above the ankle and data were collected from surgical records. Survival status after three years was assessed from the national death registry in Sweden.

Vascular examinations were performed with Periflux 5000 diagnostic instrument, in room temperature, with patients in a supine resting position, breathing normal air. ABI was calculated as ankle pressure divided by arm blood pressure and was measured on both legs. A threshold of $<0.9$ or $\geq 1.4$ was used to define pathologically low or high $\mathrm{ABI}$ [13]. Before categorizing abnormally high and abnormally low ABI together as pathological ABI, we first performed separate survival analysis for these two groups. $\mathrm{TcPO}_{2}$ measurements were performed at the dorsum of both feet. A cutpoint of $\mathrm{TcPO}_{2}<30 \mathrm{mmHg}$ was used in our analyses [14]. For mortality analysis we used the lowest $\mathrm{TcPO}_{2}$, and the lowest or highest value of ABI of the two separate legs, while the value of the ulcered leg was used when evaluating ulcer healing and amputations. Patients were stratified into three groups; group 1: both pathological $\mathrm{ABI} /$ low $\mathrm{TcPO}_{2}$, group 2: pathological $\mathrm{ABI}$ or low $\mathrm{TcPO}_{2}$ and group 3: nor$\mathrm{mal} \mathrm{ABI} / \mathrm{TcPO}_{2}$.

Baseline characteristics at the time for vascular examination, included medical history regarding prevalent cardiovascular disease (CVD) which was defined as myocardial infarction, previous coronary intervention, angina pectoris, heart failure or cerebrovascular disease. Further data on diabetes duration, smoking habits (ever), on-going medications, and laboratory data (plasma creatinine, $\mathrm{HbA} 1 \mathrm{c}$, lipids) were assessed from patient charts.

Hypertension was defined as blood pressure $\geq 140 / 90$ or use of antihypertensive drugs. Hyperlipidaemia was defined as total cholesterol of $>5 \mathrm{mmol} / \mathrm{l}$ and/or LDL-cholesterol $>2.5 \mathrm{mmol} / \mathrm{l}$ or use of cholesterol lowering drugs. MDRD-equation was used to calculate estimated glomerular filtration rate (eGFR) and renal impairment was defined as an eGFR $<60 \mathrm{ml} / \mathrm{min} / 1.73 \mathrm{~m}^{2}$ [15].

Ethical approval was given by the regional ethical committee in Lund, Sweden, and patients were asked for informed consent.

\section{Statistical analyses}

All statistical analyses were performed by use of SPSS version 25 (IBM, IL, USA). Baseline demographic data are presented as median and interquartile range (IQR) for continuous data, and as percentages (\%) for categorical data. Comparisons between groups were performed with Kruskal-Wallis one-way ANOVA test or with Chi 2 tests. Kaplan-Meier methodology with Log-rank test was used to evaluate mortality between groups. To adjust for plausible confounders, we used Cox proportional hazard models to assess hazard ratios (HR) with 95\% confidence intervals (CIs). Variables with well-known impact on mortality, such as age, previous CVD and renal dysfunction, as well as those variables that differed between groups at baseline were stepwise entered into the model. Those variables with either an independent impact on mortality or that changed the coefficient of our principal variables were then kept in the final Cox model. A two-tailed $p$ value $<0.05$ were considered statistically significant.

\section{Results}

Two hundred and thirty-five patients with a median age of 76.0 years were recruited in the study. Table 1 shows the baseline demographic of the study population, stratified into the three different groups of different $\mathrm{ABI} / \mathrm{TcPO}_{2}$ combinations. In the group with only one pathological variable the majority $(86.7 \%$ ) had a pathological ABI, whereas $13.3 \%$ had a $\mathrm{TcPO}_{2}<30 \mathrm{mmHg}$. Patients with both pathological $\mathrm{ABI}$ and low $\mathrm{TcPO}_{2}$ were more likely to be female, to have renal impairment, and more likely to have an adverse cardiovascular risk profile. There were no statistical differences regarding age, diabetes duration, $\mathrm{HbA}_{1 \mathrm{c}}$ or hyperlipidaemia between the groups. The combination of a low $\mathrm{TcPO}_{2}$ level and a pathological ABI was significantly associated with worse ulcer healing rates and higher rates of major amputation during the follow-up period, as demonstrated in Table 2 . 
Table 1 Baseline characteristics of the study population stratified by $\mathrm{ABI}$ and $\mathrm{TcPO}_{2}$
Table 2 Differences in ulcer healing, revascularization and major amputation during follow-up in patients stratified by baseline $\mathrm{ABI}$ and $\mathrm{TcPO}_{2}$

\begin{tabular}{|c|c|c|c|c|}
\hline & $\begin{array}{l}\text { Normal ABI } \\
\text { and } \\
\mathrm{TCPO}_{2} \geq 30 \mathrm{mmHg}\end{array}$ & $\begin{array}{l}\mathrm{ABI}<0.9 \text { or } \geq 1.4 \\
\text { or } \\
\mathrm{TcPO}_{2}<30 \mathrm{mmHg}\end{array}$ & $\begin{array}{l}\mathrm{ABI}<0.9 \text { or } \geq 1.4 \\
\text { and } \\
\mathrm{TcPO}_{2}<30 \mathrm{mmHg}\end{array}$ & $p$ value \\
\hline$N=235$ & 60 & 128 & 47 & \\
\hline Age (years) & $75.0(67.3-81.0)$ & $77.0(69.0-83.0)$ & $75.0(71.0-82.0)$ & n.s \\
\hline Diabetes duration (years) & $15.0(6.3-22.0)$ & $15.0(8.0-22.3)$ & $18.0(10.0-25.5)$ & n.s \\
\hline HbA1c $(\%$ DCCT $)(\mathrm{mmol} / \mathrm{mol})$ & $\begin{array}{l}7.4(6.5-8.5) \\
57(47-69)\end{array}$ & $\begin{array}{l}7.6(6.7-8.6) \\
60(50-70)\end{array}$ & $\begin{array}{l}7.2(6.4-8.6) \\
55(46-70)\end{array}$ & n.s \\
\hline eGFR $\mathrm{ml} / \mathrm{min} / 1.73$ & $69(53-92)$ & $61(43-86)$ & $49(30-64)$ & 0.000 \\
\hline Sex (\% females) & 23.3 & 27.3 & 44.7 & 0.039 \\
\hline Insulin treated $(\%)$ & 70.0 & 68.8 & 74.5 & n.s \\
\hline Sulphonylurea (\%) & 15.3 & 10.2 & 6.4 & n.s \\
\hline Metformin (\%) & 50.8 & 36.2 & 27.7 & 0.041 \\
\hline SGLT 2 inhibitors (\%) & 1.7 & 0.8 & 0.0 & n.s \\
\hline Incretins (\%) & 6.8 & 8.6 & 4.3 & n.s \\
\hline Aspirin & 56.9 & 49.2 & 59.6 & n.s \\
\hline Anticoagulants & 16.9 & 30.7 & 27.7 & n.s \\
\hline Smoking, ever (\%) & 13.5 & 28.8 & 35.9 & 0.035 \\
\hline Hypertension (\%) & 88.3 & 97.7 & 93.6 & 0.026 \\
\hline Hyperlipidemia (\%) & 87.3 & 85.5 & 90.9 & n.s \\
\hline CVD (\%) & 51.7 & 67.2 & 76.6 & 0.021 \\
\hline $\begin{array}{l}\mathrm{ABI}<0.9(\%) \\
\mathrm{ABI} \geq 1.4(\%)\end{array}$ & $\begin{array}{l}0 \\
0\end{array}$ & $\begin{array}{l}73.4 \\
13.3\end{array}$ & $\begin{array}{l}91.5 \\
8.5\end{array}$ & 0.000 \\
\hline $\mathrm{TcPO} 2<30 \mathrm{mmHg}$ & 0 & 13.3 & 100 & 0.000 \\
\hline
\end{tabular}

Data are expressed as median (IQR) or percentages. $P$ values $<0.1$ are shown; otherwise n.s is stated

\begin{tabular}{|c|c|c|c|c|}
\hline & $\begin{array}{l}\text { Normal ABI } \\
\text { and } \\
\mathrm{TCPO}_{2} \geq 30 \mathrm{mmHg}\end{array}$ & $\begin{array}{l}\mathrm{ABI}<0.9 \text { or } \geq 1.4 \\
\mathrm{Or} \\
\mathrm{TcPO}_{2}<30 \mathrm{mmHg}\end{array}$ & $\begin{array}{l}\mathrm{ABI}<0.9 \text { or } \geq 1.4 \\
\text { and } \\
\mathrm{TcPO}_{2}<30 \mathrm{mmHg}\end{array}$ & $p$ value \\
\hline Vascular intervention (\%) & 3.3 & 20.2 & 35.0 & 0.000 \\
\hline Endovascular (\% of total) & 100.0 & 81.8 & 86.7 & \\
\hline Surgical & 0 & 18.2 & 6.7 & \\
\hline Both endovascular and surgical & 0 & 0 & 6.7 & \\
\hline Healed within 3 months (\%) & 34.4 & 17.5 & 12.5 & 0.004 \\
\hline Healed within 1 year (\%) & 70.0 & 54.4 & 42.5 & 0.007 \\
\hline Major amputation (\%) & 5.5 & 4.4 & 25.0 & 0.000 \\
\hline
\end{tabular}

Data are expressed as percentages
The relative risk of having an unhealed ulcer after one year was 1.9 (95\% CI 1.3-2.9) and the risk of having a major amputation was 4.6 (95\% CI 1.8-13.2) among individuals with both pathological $\mathrm{ABI}$ and a low $\mathrm{TcPO}_{2}$ compared to those with normal values.

During the three years of follow-up, $43 \%$ of our participants died. There was no difference in mortality rate between the groups of individuals with a low $\mathrm{ABI}<0.9$ compared to those with abnormally high $\mathrm{ABI} \geq 1.4(p=0.569)$. As demonstrated in Fig. 1, both high and low ABI were significantly associated with increased three-year mortality compared to normal ABI $(p=0.002)$. The highest mortality rate was seen in the group of the individuals with a combination of either a high or low ABI together with a low $\mathrm{TcPO}_{2}$, as demonstrated in Fig. 2. The three-year mortality among these patients was $55.3 \%$, compared to $47.7 \%$ in the group with only one pathological vascular parameter, and $23.3 \%$, in those having normal $\mathrm{ABI}$ and $\mathrm{TcPO}_{2}$ levels $(p<0.003)$. Cox regression models were performed to adjust for plausible confounders, such as differences in baseline characteristics and other well-known risk factors for mortality (age, gender, smoking, diabetes duration, CVD, eGFR $<60 \mathrm{ml} / \mathrm{min} / 1.73 \mathrm{~m}^{2}$, hypertension, revascularization, ulcer healing at three months and major amputation). Hypertension, gender, smoking, eGFR 


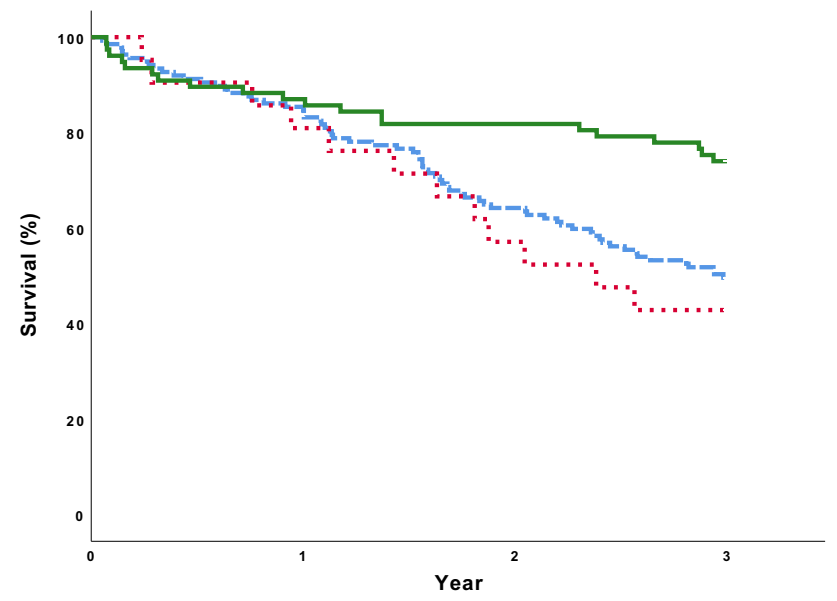

Fig. 1 Kaplan-Meier survival curves analyzed with Log-rank test, for the primary endpoint of mortality during the three year of follow-up, within the different groups of ABI. Green solid line: Individuals with normal ABI. Blue dashed line: Individuals with $\mathrm{ABI}<0.9$. Red dotted line: Individuals with $\mathrm{ABI} \geq 1.4$. $p=0.002$ comparing normal $\mathrm{ABI}$ with either $\mathrm{ABI}<0.9$ or $\mathrm{ABI} \geq 1.4$. $p=0.569$ comparing $\mathrm{ABI}<0.9$ with $\mathrm{ABI} \geq 1.4$.

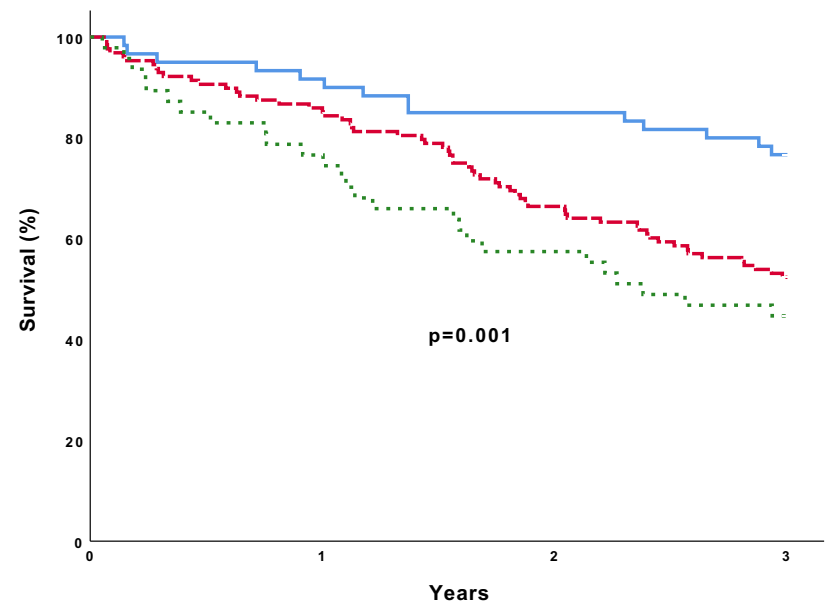

Fig. 2 Kaplan-Meier survival curves with Log-rank test, for the primary endpoint of mortality during the three year of follow-up when combining $\mathrm{ABI}$ and $\mathrm{TcPO}_{2}$. Blue solid line: Individuals with normal $\mathrm{ABI}$ and $\mathrm{TcPO}_{2} \geq 30 \mathrm{mmHg}$. Red dashed line: Individuals with either pathological $\mathrm{ABI}(<0.9$ or $\geq 1.4)$ or low $\mathrm{TcPO}_{2}<30 \mathrm{mmHg}$. Green dotted line: Individuals with both pathologically $\mathrm{ABI}$ and low $\mathrm{TcPO}_{2}$

and major amputation were not independently associated with mortality, nor found to be confounders behind the results and were thus not entered in the final Cox model. The result of the final multivariate Cox model is given in Table 3. In this analysis, the combination of a pathological $\mathrm{ABI}$ and a low $\mathrm{TcPO}_{2}$ was the strongest independent predictor of mortality, with a HR of 2.19 (1.11-4.33). If only one parameter was pathological (ABI or $\left.\mathrm{TcPO}_{2}\right)$ no significant association was found after adjustment [HR was 1.78
Table 3 Predictors for three-year mortality based on the final multivariate Cox regression model

\begin{tabular}{llll}
\hline & $\begin{array}{l}\text { Adjusted } \\
\text { hazard } \\
\text { ratio }\end{array}$ & $95 \%$ CI & $p$ value \\
& $1.78 *$ & $0.97-3.26$ & 0.063 \\
$\begin{array}{l}\mathrm{ABI}<0.9 \text { or } \geq 1.4 \\
\text { or } \\
\mathrm{TcPO}_{2}<30 \mathrm{mmHg} \\
\mathrm{ABI}<0.9 \text { or } \geq 1.4\end{array}$ & $2.19 *$ & $1.11-4.33$ & 0.024 \\
$\begin{array}{l}\text { and } \\
\mathrm{TcPO}\end{array}$ & & & \\
$\begin{array}{l}\mathrm{Age}(\text { one year increase) } \\
\text { Diabetes duration (one year } \\
\text { increase) }\end{array}$ & 1.06 & $1.03-1.09$ & 0.000 \\
$\begin{array}{l}\text { Ulcer healing at 3 months } \\
\text { Cardiovascular disease }\end{array}$ & 1.02 & $1.00-1.05$ & 0.026 \\
\hline
\end{tabular}

*Compared to individuals with normal $\mathrm{ABI}$ and $\mathrm{TcPO}_{2}$ as the reference group

(0.97-3.26)]. Ulcer healing after three months, the presence of CVD, diabetes duration and age were also independently associated with mortality.

\section{Discussion}

Prediction of wound healing and major amputation in patients with diabetic foot ulceration is clinically important both to stratify risk and target interventions for limb salvage. However, predictors for ulcer outcome might also have major impact on survival. Our study confirms that mortality among individuals with DFU is still alarmingly high, despite a high technological and improved quality health care over the last decades. Forty-three percent of our study participants died during the three-year of follow-up. This indicates a need for valuable tools for risk stratification, and a raised awareness for the diabetic foot patient. In our study, we have demonstrated that the combination of an abnormal $\mathrm{ABI}$ (high or low) and a low $\mathrm{TcPO}_{2}$, might help us to identify high-risk patients with urgent need for multifactorial intervention not only improving peripheral circulation, but also to reduce life-threatening complications. Our results indicates that the combination of a pathologically high or low $\mathrm{ABI}$ and a low $\mathrm{TcPO}_{2}$ is associated with a more than twofold increase in three-year mortality compared to normal $\mathrm{ABI} / \mathrm{TcPO}_{2}$. In a German cohort of 247 patients with DFU, Morbach et al. reported a $33.1 \%$ three-year mortality in the whole DFU-population, and among those with PVD at baseline, defined by $\mathrm{ABI}<0.9$ mortality was $44.1 \%$ [16]. Our mortality rate was higher, which might reflect an older study population in our study compared to Morbach's trial (68.8 vs. 76.0 years). The high mortality rate among DFU-patients has traditionally been explained by a higher 
burden of traditional macrovascular complications. An ABI 0.9 correlates frequently with other coexisting macrovascular complications and has in previous studies been shown to predict both fatal and non-fatal cardiovascular events, as well as all-cause mortality [6,8]. In our study, both high as well as low ABI seem to be risk factors for mortality, consistent with previous studies [17]. We also found that individuals with $\mathrm{ABI}<0.9$ were more likely to have coexisting CVD, compared to those with normal ABI (71.5 vs. $57.1 \%$ $p=0.031$ ). However, this was not seen in the group with elevated ABI (52.4\%). However, the number of patients with elevated ABI was small $(n=21)$, and thus conclusions must be drawn cautiously. Further, we lack data on the separate diagnosis included in the composite CVD diagnose, and thus we cannot exclude differences in the distribution between the groups.

In DFU patients the vascular condition is often complex [9]. There are some important limitations with ABI measurements in diabetes and especially among those with neuropathy [18]. Due to medial arterial calcifications, there is a risk of falsely elevated ABIs underestimating the severity of PVD [19, 20]. Further, coexisting microvascular complications, such as diabetic kidney disease and neuropathy, often contributes to the poor prognosis both concerning ulcer healing and survival. Previous studies have shown that a low $\mathrm{TcPO}_{2}$ has been associated with a higher burden of other microvascular complications as well as an increased risk of major cardiovascular events [12, 21]. In our study, patients with pathological $\mathrm{ABI}$ and a low $\mathrm{TcPO}_{2}$ were more likely to have reduced renal function, result consistent with other studies [22-24]. Another often overlooked microvascular complication of diabetes that frequently co-exists in DFUpatients with distal polyneuropathy and microangiopathy is cardiovascular autonomic neuropathy (CAN). In a large meta-analysis of 15 studies including 2500 patients with diabetes, the presence of CAN was a strong predictor for mortality with a relative risk of 3.5 (95\% CI 2.66-4.47) [25]. In our study, we lack quantitative data on neuropathy and CAN, which is a limitation. From other studies evaluating DFU individuals, it is likely that the prevalence of neuropathy in our population is high. For example, in the large multicenter trial EURODIALE the prevalence of neuropathy was $86 \%$ in DFU patients [26]. However, since we lack data in our trial, we can only speculate about a plausible association between $\mathrm{TcPO}_{2}$, peripheral neuropathy and CAN, and their role for mortality.

It is previous well demonstrated that ulcer healing is compromised in patients with low $\mathrm{ABI}$ as well as in those with a low $\mathrm{TcPO}_{2}[14,27,28]$. This was also confirmed in our study. The worse healing rate and a significant increase in major amputations were seen among those with a combination of pathological $\mathrm{ABI} /$ low $\mathrm{TcPO}_{2}$, indicating that these patients might need an even more urgent vascular evaluation.
There was an unexpectedly low revascularization rate among our patients. In the group with both pathological ABI/low $\mathrm{TcPO}_{2}$, only $35 \%$ performed a vascular intervention. When analyzing the data, we found additional $20 \%$ who were assessed by a vascular surgeon, but intervention either failed or was considered too hazardous. Among the remaining 45\% there were individuals not suitable for intervention because of multiple severe comorbidities, renal failure, and a few cases with significant ulcer improvement without vascular intervention. However, there were still a small number of patients without any rational behind why no vascular evaluation was performed. When comparing our results with others, we can conclude that our finding is not unique, indicating a general need for improvement in the management of the diabetic foot. For example, the large study EURODIALE demonstrated that $56 \%$ of the patients with critical limb ischemia performed vascular imaging, and of them, only $43 \%$ were revascularized [29]. Further, Malyar et al. reported revascularization rates of $18 \%$ and angiography rates of $25 \%$ in their study population [6]. We cannot tell whether a higher rate of vascular intervention would have had positive affect on our amputation rates and on survival. There was a nonsignificant trend towards better survival among individuals with pathological $\mathrm{ABI} /$ low $\mathrm{TcPO}_{2}$ who underwent a revascularization in our study. However, this could just as well be the result of a less complex comorbidity, rather than a result of the revascularization per se. In addition, neither revascularization nor major amputation rates turned out to be independent predictors for survival in our study. Similar result was demonstrated in a study by Faglia et al. In that study, $28.2 \%$ of the individuals who underwent a vascular intervention due to critical limb ischemia died, compared to $81.6 \%$ of the patients who did not undergo such procedure. However, after adjusting for several risk factors in that study, only age turned out to predict mortality and was considered a confounding factor [30]. Nevertheless, vascular intervention has profound impact on wound healing, which also turned out to be a protective factor for survival in our study.

Traditionally, male gender is considered a risk factor for developing foot ulcers and previous studies has also reported male gender as a risk factor for amputation [23]. Also, in our trial the majority $(70 \%)$ of all patients were men, but one unexpected finding in our trial was the high rate of females among those with worse peripheral circulation. One plausible explanation behind this finding might be that our female participants were older ( 81 vs. 75 years $p=0.007$ ) and had worse renal function (eGFR 54 vs. $64 \mathrm{ml} / \mathrm{min} / 1.73$, $p=0.017$ ) compared with males. However, after adjusting for age and renal function, gender was not independently associated with mortality. Although our study population was relatively large, we cannot exclude a limitation in statistical power that enables us to detect small differences in other important risk factors and thus, conclusions regarding 
these must be drawn cautiously. Further, we cannot exclude a selection bias, as we only included individuals who were vascular examined at our department. There might thus be few patients with ulcers that healed promptly, as well as few individuals with acute limb-threatening ischemia admitted straight into acute hospital care, who might not have been vascular examined at our department, and consequently not included in our study. This could have influenced both the demographics of our study population as well as outcome. It is however unlikely, that lacking few individuals within these two subgroups would diminish the risk of a pathological $\mathrm{ABI}$ and $\mathrm{TcPO}_{2}$ on mortality. Despite these limitations, our DFU cohort represents a relatively large "real-world" cohort, with a robust primary endpoint, not accomplished with any biases.

In conclusion, our study confirms that mortality among individuals with DFU is still alarmingly high, and the need of a more aggressive approach towards cardiovascular risk factor management is crucial. Combining two non-invasive vascular screening methods, $\mathrm{TcPO}_{2}$ and $\mathrm{ABI}$, provides important predictive information which might help us to risk stratify individuals, identifying those with urgent need for interventions not only targeting limb salvage, but also targeting survival.

Author's contribution KF, PK and ML contributed to the design of the study. KF and ML performed data and statistical analysis. KF wrote, and all authors reviewed the article. ML is the guarantor of this work and is responsible for integrity and accuracy of data.

Funding Open access funding provided by Lund University. This study was supported by the Swedish Diabetes Foundation, Skåne County council's research and development foundation and faculty of Medicine (ALF), Lund University, Sweden.

\section{Declarations}

Conflict of interest The authors declare that they have no conflict of interest.

Ethical standards All procedures performed in studies involving human participants were in accordance with the ethical standards of Ethics Committee in Lund, Sweden and with the 1964 Helsinki declaration and its later amendments or comparable ethical standards. Approval of the study was given by the Ethics Committee in Lund, Sweden.

Informed consent Informed consent was obtained from all individual participants included in the study.

Open Access This article is licensed under a Creative Commons Attribution 4.0 International License, which permits use, sharing, adaptation, distribution and reproduction in any medium or format, as long as you give appropriate credit to the original author(s) and the source, provide a link to the Creative Commons licence, and indicate if changes were made. The images or other third party material in this article are included in the article's Creative Commons licence, unless indicated otherwise in a credit line to the material. If material is not included in the article's Creative Commons licence and your intended use is not permitted by statutory regulation or exceeds the permitted use, you will need to obtain permission directly from the copyright holder. To view a copy of this licence, visit http://creativecommons.org/licenses/by/4.0/.

\section{References}

1. Abbott CA, Carrington AL, Ashe H, North-West Diabetes Foot Care S et al (2002) The North-West Diabetes Foot Care Study: incidence of, and risk factors for, new diabetic foot ulceration in a community-based patient cohort. Diabet Med 19(5):377-384

2. Siitonen OI, Niskanen LK, Laakso M, Siitonen JT, Pyorala K (1993) Lower-extremity amputations in diabetic and nondiabetic patients A population-based study in eastern Finland. Diabetes Care 16(1):16

3. Iversen MM, Tell GS, Riise T et al (2009) History of foot ulcer increases mortality among individuals with diabetes: ten-year follow-up of the Nord-Trondelag health study Norway. Diabetes Care 32(12):2193-2199. https://doi.org/10.2337/dc09-0651

4. Brownrigg JR, Davey J, Holt PJ et al (2012) The association of ulceration of the foot with cardiovascular and all-cause mortality in patients with diabetes: a meta-analysis. Diabetologia 55(11):2906-2912. https://doi.org/10.1007/s00125-012-2673-3

5. Apelqvist J, Larsson J, Agardh CD (1993) Long-term prognosis for diabetic patients with foot ulcers. J Intern Med 233(6):485-491

6. Malyar NM, Freisinger E, Meyborg M et al (2016) Amputations and mortality in in-hospital treated patients with peripheral artery disease and diabetic foot syndrome. J Diabetes Complicat 30(6):1117-1122. https://doi.org/10.1016/j.jdiacomp.2016.03.033

7. Criqui MH, Langer RD, Fronek A et al (1992) Mortality over a period of 10 years in patients with peripheral arterial disease. N Engl J Med 326(6):381-386. https://doi.org/10.1056/NEJM1 99202063260605

8. Hanssen NM, Huijberts MS, Schalkwijk CG, Nijpels G, Dekker JM, Stehouwer CD (2012) Associations between the ankle-brachial index and cardiovascular and all-cause mortality are similar in individuals without and with type 2 diabetes: nineteen-year follow-up of a population-based cohort study. Diabetes Care 35(8):1731-1735. https://doi.org/10.2337/dc12-0178

9. Mohammedi K, Woodward M, Marre M et al (2017) Comparative effects of microvascular and macrovascular disease on the risk of major outcomes in patients with type 2 diabetes. Cardiovasc Diabetol 16(1):95. https://doi.org/10.1186/s12933-017-0574-y

10. Mayrovitz HN, Larsen PB (1996) Functional microcirculatory impairment: a possible source of reduced skin oxygen tension in human diabetes mellitus. Microvasc Res 52(2):115-126. https:// doi.org/10.1006/mvre.1996.0048

11. Fagher K, Katzman P, Londahl M (2018) Transcutaneous oxygen pressure as a predictor for short-term survival in patients with type 2 diabetes and foot ulcers: a comparison with ankle-brachial index and toe blood pressure. Acta Diabetol 55(8):781-788. https://doi. org/10.1007/s00592-018-1145-8

12. Gazzaruso C, Coppola A, Falcone C et al (2013) Transcutaneous oxygen tension as a potential predictor of cardiovascular events in type 2 diabetes: comparison with ankle-brachial index. Diabetes Care 36(6):1720-1725. https://doi.org/10.2337/dc12-1401

13. Hinchliffe RJ, Brownrigg JR, Apelqvist J, International Working Group on the Diabetic F et al (2016) IWGDF guidance on the diagnosis, prognosis and management of peripheral artery disease in patients with foot ulcers in diabetes. Diabetes Metab Res Rev 32(Suppl 1):37-44. https://doi.org/10.1002/dmrr.2698 
14. Ballard JL, Eke CC, Bunt TJ, Killeen JD (1995) A prospective evaluation of transcutaneous oxygen measurements in the management of diabetic foot problems. J Vasc Surg. 22(4):485-490 (discussion 490-482)

15. Levey AS, Coresh J, Greene T et al (2006) Using standardized serum creatinine values in the modification of diet in renal disease study equation for estimating glomerular filtration rate. Ann Intern Med 145(4):247-254

16. Morbach S, Furchert H, Groblinghoff U et al (2012) Long-term prognosis of diabetic foot patients and their limbs: amputation and death over the course of a decade. Diabetes Care 35(10):20212027. https://doi.org/10.2337/dc12-0200

17. Resnick HE, Lindsay RS, McDermott MM et al (2004) Relationship of high and low ankle brachial index to all-cause and cardiovascular disease mortality: the Strong Heart Study. Circulation 109(6):733-739. https://doi.org/10.1161/01.CIR.0000112642. 63927.54

18. Brownrigg JR, Hinchliffe RJ, Apelqvist J, International Working Group on the Diabetic F et al (2016) Effectiveness of bedside investigations to diagnose peripheral artery disease among people with diabetes mellitus: a systematic review. Diabetes Metab Res Rev 32(Suppl 1):119-127. https://doi.org/10.1002/dmrr.2703

19. Jeffcoate WJ, Rasmussen LM, Hofbauer LC, Game FL (2009) Medial arterial calcification in diabetes and its relationship to neuropathy. Diabetologia 52(12):2478-2488. https://doi.org/10. 1007/s00125-009-1521-6

20. Faglia E, Clerici G, Caminiti M, Quarantiello A, Curci V, Somalvico F (2010) Evaluation of feasibility of ankle pressure and foot oximetry values for the detection of critical limb ischemia in diabetic patients. Vasc Endovascular Surg 44(3):184-189. https:// doi.org/10.1177/1538574409359430

21. Huang K, Ma Y, Wang J et al (2017) The correlation between transcutaneous oxygen tension and microvascular complications in type 2 diabetic patients. J Diabetes Complicat 31(5):886-890. https://doi.org/10.1016/j.jdiacomp.2017.02.006

22. Leskinen Y, Salenius JP, Lehtimaki T, Huhtala H, Saha H (2002) The prevalence of peripheral arterial disease and medial arterial calcification in patients with chronic renal failure: requirements for diagnostics. Am J Kidney Dis 40(3):472-479. https://doi.org/ 10.1053/ajkd.2002.34885

23. Bruun C, Siersma V, Guassora AD, Holstein P, de Fine Olivarius $\mathrm{N}$ (2013) Amputations and foot ulcers in patients newly diagnosed with type 2 diabetes mellitus and observed for 19 years: the role of age, gender and co-morbidity. Diabet Med 30(8):964-972. https:// doi.org/10.1111/dme.12196

24. Wolf G, Muller N, Busch M et al (2009) Diabetic foot syndrome and renal function in type 1 and 2 diabetes mellitus show close association. Nephrol Dial Transplant 24(6):1896-1901. https:// doi.org/10.1093/ndt/gfn724

25. Maser RE, Mitchell BD, Vinik AI, Freeman R (2003) The association between cardiovascular autonomic neuropathy and mortality in individuals with diabetes: a meta-analysis. Diabetes Care 26(6):1895-1901

26. Prompers L, Huijberts M, Apelqvist J et al (2007) High prevalence of ischaemia, infection and serious comorbidity in patients with diabetic foot disease in Europe: baseline results from the Eurodiale study. Diabetologia 50(1):18-25. https://doi.org/10.1007/ s00125-006-0491-1

27. Kalani M, Brismar K, Fagrell B, Ostergren J, Jorneskog G (1999) Transcutaneous oxygen tension and toe blood pressure as predictors for outcome of diabetic foot ulcers. Diabetes Care 22(1):147-151

28. Jude EB, Oyibo SO, Chalmers N, Boulton AJ (2001) Peripheral arterial disease in diabetic and nondiabetic patients: a comparison of severity and outcome. Diabetes Care 24(8):1433-1437

29. Prompers L, Huijberts M, Apelqvist J et al (2008) Delivery of care to diabetic patients with foot ulcers in daily practice: results of the Eurodiale Study, a prospective cohort study. Diabet Med 25(6):700-707. https://doi.org/10.1111/j.1464-5491.2008.02445.x

30. Faglia E, Clerici G, Caminiti M et al (2010) Mortality after major amputation in diabetic patients with critical limb ischemia who did and did not undergo previous peripheral revascularization data of a cohort study of 564 consecutive diabetic patients. J Diabetes Complicat 24(4):265-269. https://doi.org/10.1016/j.jdiacomp. 2009.02.004

Publisher's Note Springer Nature remains neutral with regard to jurisdictional claims in published maps and institutional affiliations. 